\title{
Output Gap Uncertainty and Monetary Policy During the 1970s
}

David E. Spencer

david_spencer@byu.edu

Follow this and additional works at: https://scholarsarchive.byu.edu/facpub

Part of the Economics Commons

\section{Original Publication Citation}

Spencer, David E. (24) "Output Gap Uncertainty and Monetary Policy During the 197s," Topics in Macroeconomics: Vol. 4 : Iss. 1, Article 2.

\section{BYU ScholarsArchive Citation}

Spencer, David E., "Output Gap Uncertainty and Monetary Policy During the 1970s" (2004). Faculty Publications. 453.

https://scholarsarchive.byu.edu/facpub/453 


\title{
Topics in Macroeconomics
}

Volume 4, Issue 1

2004

Article 2

\section{Output Gap Uncertainty and Monetary Policy During the 1970s}

\author{
David E. Spencer*
}

*Brigham Young University, david_spencer@byu.edu

Copyright (C)2004 by the authors. All rights reserved. No part of this publication may be reproduced, stored in a retrieval system, or transmitted, in any form or by any means, electronic, mechanical, photocopying, recording, or otherwise, without the prior written permission of the publisher, bepress, which has been given certain exclusive rights by the author. Topics in Macroeconomics is produced by The Berkeley Electronic Press (bepress). http://www.bepress.com/bejm 


\title{
Output Gap Uncertainty and Monetary Policy During the $1970 \mathrm{~s}^{*}$
}

\author{
David E. Spencer
}

\begin{abstract}
The conduct of monetary policy during the 1970s was greatly complicated by systematic realtime misperceptions of the state of economic activity as measured by the output gap. Employing real-time data and using the Taylor rule as an analytical framework, I explore the implications of utilizing alternative observable proxies for the unobservable output gap. I compare the counterfactual paths for the federal funds rate generated under each proxy with the actual path of the federal funds rate and a benchmark ( "ideal") path implied by a full information Taylor rule. Results suggest that these real-time proxies would have resulted in better policy outcomes than actually occurred. Indeed, the federal funds rate path that comes closest to the ideal path occurs when the estimate of the output gap is taken to be zero (its steady-state value) at every point in time. This is equivalent to ignoring output gap information in monetary policy decisions.
\end{abstract}

KEYWORDS: Monetary policy, Taylor rule, Output gap

*I am grateful to Philip Garner and Brad Strum for comments on an earlier draft of this paper and to Rick Evans for excellent research assistance. I also express appreciation for helpful comments from the editor and two anonymous referees. Address: Department of Economics, 130 FOB, Brigham Young University, Provo UT 84602 


\section{INTRODUCTION}

Spencer: Monetary Policy During the 1970s

There seems to be near unanimity in the belief that U.S. monetary policy failed during the 1970s. Justification for such a belief is confirmed by comparing the performance of key measures of aggregate economic activity during that decade with their performance during a more recent decade in which monetary policy has been broadly judged to be quite successful. Table 1 reports such summary statistics comparing the decade before the appointment of Paul Volcker as chairman of the Board of Governors of the Federal Reserve System (Fed), 1969:3-1979:2, with the first decade of Alan Greenspan's chairmanship, 1987:3-1997:2. The first column reveals the significant difference in the behavior of inflation (measured using the GDP Deflator). During the 1970s the mean rate of inflation was much higher and inflation was much more variable than during the latter period. There was also much greater variation in output (real GDP) growth during the 1970s with little difference in the average rate of growth. Furthermore, the absolute value of the output gap as a percentage (estimated by the Congressional Budget Office (CBO)) was much larger on average and characterized by much more variation while the average unemployment rate was essentially the same over the two decades but much more variable during the 1970s that during the Greenspan decade. These observations support the view that the 1970s was an economically troubled time and admit the possibility that monetary policy may have failed in some important way.

Several studies have investigated the role of monetary policy as a partial explanation for poor economic performance during the 1970s. Two principle explanations seem to dominate. The first, supported by Judd and Rudebusch (1998), Taylor (1999b), Clarida, Gali, and Gertler (2000), and Mehra (2002), is that the Federal Reserve was insufficiently responsive to inflation during that decade. Consequently, policies were pursued that failed to resist inflationary pressure. The second explanation, argued principally by Orphanides in a sequence of influential papers, ${ }^{1}$ is that the Fed did respond sufficiently to inflation but systematically misperceived the state of the economy. ${ }^{2}$ Real-time perceptions of the output gap that turned out to be too pessimistic led policymakers to pursue a policy that, in retrospect, accommodated inflation. It is interesting to note that these different conclusions have been arrived at using the Taylor rule ${ }^{3}$ as a common analytical framework but employing different data concepts. Except for Mehra (2002), the first group of studies uses data that have undergone historical revision that could not have been anticipated by policymakers in real time. Orphanides contends that using such revised data can lead to distorted empirical conclusions. He has argued convincingly that analysis of historical policy behavior requires the use of real-time data that were actually available to policymakers at the time policy choices were made.

Without taking a direct stand against either of these explanations, ${ }^{4}$ this paper also uses the Taylor rule framework and real-time data to ask whether the Fed could have done better during the 1970s. I start with the proposition that the Taylor rule produces generally good monetary policy outcomes when the policy authorities correctly perceive the state of the economy; i.e.,

1 A useful selection of these papers would include Orphanides (2000, 2002a, 2002b).

2 Perez (2001) also finds evidence that the Fed responded significantly to (expected) inflation. However, his explanation for the failure of monetary policy during the 1970s differs from that of Orphanides though they both use real-time data.

3 According to the Taylor rule, proposed by Taylor (1993), the monetary authority changes its target short-term interest rate in response to movements in the rate of inflation and the output gap. Specifics are presented in the next section.

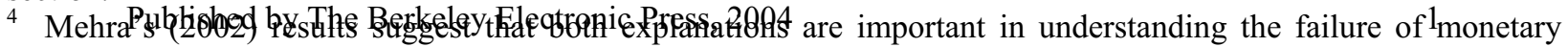
policy during the 1970s. 
Table 1: U.S. Mapics in Macroeconomics, Vol. 4 [2004], Iss. 1 Art ${ }^{2}$ '

\begin{tabular}{lcccc}
\hline Period & $\begin{array}{c}\text { Inflation } \\
\text { (s.d.) }\end{array}$ & $\begin{array}{c}\text { Output growth rate } \\
\text { (s.d.) }\end{array}$ & $\begin{array}{c}\text { Absolute output gap } \\
\text { (s.d.) }\end{array}$ & $\begin{array}{c}\text { Unemployment rate } \\
\text { (s.d.) }\end{array}$ \\
\hline $\begin{array}{l}\text { 1969:3-1979:2 } \\
\text { (Pre-Volcker) }\end{array}$ & $\begin{array}{c}6.35 \\
(2.07)\end{array}$ & 3.15 & 2.11 & 6.08 \\
1987:3-1997:2 & 2.76 & $(4.46)$ & $(1.50)$ & $(1.34)$ \\
(Greenspan) & $(0.94)$ & $(2.22)$ & 1.32 & 6.05 \\
\hline
\end{tabular}

Each cell reports the mean of the indicated series with its standard deviation in parentheses.

under full information about the output gap. Justification for this claim will be offered below. However, even if the full information implementation of the Taylor rule yields desirable outcomes, that rule is likely to fail when the output gap is severely misperceived. Such misperceptions are, almost surely, at least a part of the explanation for the failure of monetary policy during the 1970s. In this paper, I consider if, relying only on information that was available at the time, we can identify real-time proxies for the unobserved output gap that would have been better guides for policy during that decade. The evidence indicates very clearly that we can. Indeed, the findings reported below suggest that monetary policy would have been much better if policymakers had followed a Taylor rule and taken the output gap to be zero (its steady-state value) at every point in time. This does not reflect the inadequacy of the Taylor rule as a guide to policy but rather the profound inadequacy of real-time measures of the output gap over this period.

The purpose of this paper is not to ascertain the policy rule actually followed by the Fed during the 1970s. Consequently, I eschew estimation of policy rules. Instead, I am interested in the counterfactual path of the federal funds rate under an array of alternative real-time implementations of a standard Taylor rule.

The next section briefly reviews the standard Taylor rule framework and discusses the difficulties that arise in implementing it when the output gap is misperceived. Section III introduces four alternative monetary policy rules that address the problem of uncertainty regarding the size of the output gap and therefore hold the possibility that policy can be improved under such uncertainty. In Section IV, these proposed rules are used to generate counterfactual outcomes for the federal funds rate over the 1970s. These are compared with actual outcomes and with outcomes from a benchmark Taylor rule. The final section summarizes and offers some conclusions.

\section{The Taylor Rule Framework}

Taylor (1993) proffers a relatively simple rule that he argues broadly captures monetary policy behavior in the U.S. during 1987-1992, the early years of the Greenspan era at the Federal Reserve. According to the Taylor rule, the Fed adjusts the federal funds rate in response to changes in inflation relative to a chosen target inflation rate and in response to changes in the output gap. Taylor's seminal paper has had a pervasive influence. Many academic economists

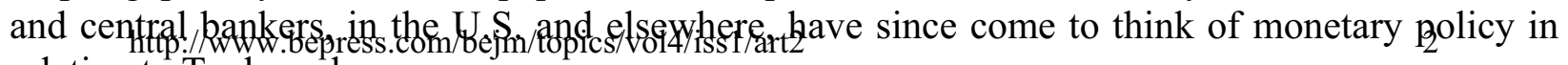
relation to Taylor rules. 


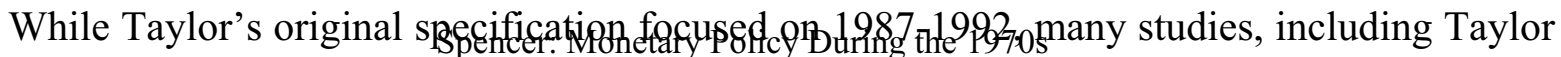
(1999b), have used the Taylor rule as an analytical framework for examining monetary policy in other periods. In particular, as indicated above, the Taylor rule has been used to examine the troubled decade of the 1970s.

The Taylor rule is given by

(1) $i_{t}=\alpha+\beta\left(\pi_{t}-\pi^{*}\right)+\gamma y_{t}$

where $i_{t}$ is the target value of the federal funds rate, $\pi_{t}$ is the current inflation rate, $\pi^{*}$ is the target inflation rate, $y_{t}$ is the current output gap, and $\alpha=r^{*}+\pi^{*}$ where $r^{*}$ is the long-run equilibrium real federal funds rate (the "natural real rate of interest"). The measured rate of inflation used by Taylor $(1993,1999 \mathrm{~b})$ is the average over the current and three previous quarters. One of the analytical attractions of the Taylor rule is its simplicity. Nevertheless, Taylor neither suggests nor believes that this rule reflects the actual process by which the Fed conducts monetary policy. It is intended as a simple but useful approximation to the much more complicated actual approach followed by policymakers.

Taylor $(1993,1999 \mathrm{~b})$ suggests the following parameterization: $r^{*}=2.0, \pi^{*}=2.0, \beta=1.5$, $\gamma=0.5{ }^{5}$ There are two reasons for this choice. First it provides a reasonably good description of Federal Reserve behavior over 1987-1992, a period of good macroeconomic performance. Secondly, it seems to generate good outcomes in terms of inflation and output stability on the basis of simulations across a variety of econometric models.

An important property of this parameterization is incorporation of the so-called "Taylor principle" which requires that $\beta>1.0$. This property assures that the nominal interest rate increases more than one-for-one with an increase in inflation thus implying that the response to an increase in inflation is an increase in the real rate of interest. A policy rule that violates the Taylor principle is likely to accommodate inflation. Indeed, the argument made by Judd and Rudebusch (1998), Taylor (1999b), Clarida, Gali, and Gertler (2000), and Mehra (2002) is that the failure of monetary policy in the 1970s was a failure to adhere to the Taylor principle.

Taylor draws his conclusions about the usefulness of this particular specification based on evaluations using revised data, thus, implicitly assuming that the difference between real-time and revised data is inconsequential. Policymakers must, of course, rely on data available at the time they are called upon to make policy decisions and such real-time data may, in fact, be quite different from revised data available years after the fact. Runkle (1998) has demonstrated that official data revisions of measures of inflation and real output growth can be substantial after a period of time. Consequently, using revised data unavailable to policymakers to evaluate their historical policy decisions is potentially quite misleading. In several papers, Orphanides (2001, 2002a, 2003) has confirmed that while using revised estimates of inflation and output can be somewhat misleading, a much more important problem is the real-time misperception of potential output and, thus, the output gap. In particular, his studies have shown that real-time estimates of the output gap may be subject to considerable systematic error for long periods of time.

So, a major obstacle to conducting policy in real time is that the true output gap is

\footnotetext{
5 Taylor assumes the $r^{*}$ and $\pi^{*}$ are both constant at 2.0. While it may be a reasonable conjecture that the inflation target was approximately two percent during the 1970's, it is more difficult to maintain the assumption of a constant "natural real rate of interest" over that period. Nevertheless, I retain Taylor's parameterization. For more on the

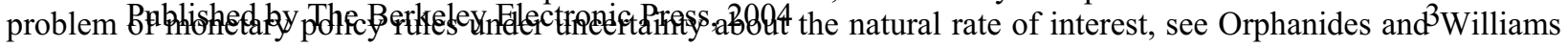
(2002).
} 
unobserved and difficult topmeasure to substantial policy mistakes. Indeed, there is, by now, wide agreement that during the 1970s, the output gap was systematically misperceived, a consequence of the failure to recognize the productivity slowdown until much later. ${ }^{6}$ This is illustrated in Figure 1 which plots two real-time output gap series along with a revised estimate of the output gap for the period 1969:3-1979:2, the period of purported policy failure. The revised output gap is given by the Congressional Budget Office (CBO) estimates as of 2003. ${ }^{7}$ The first real-time output gap measure is that used by Orphanides $(2002 \mathrm{~b}, 2003){ }^{8}$ This series is based on estimates of the output gap reported by the Council of Economic Advisors over this period and so I refer to it as the CEA real-time gap. The second real-time output gap measure is obtained by estimating one-sided linear trends using realtime data. ${ }^{9}$ The real-time output data are obtained from the compilation reported in Croushore and Stark (2001). For each quarter in the interval, I estimate a linear trend from 1953:1 to that quarter using real-time output data available in that quarter. The output gap for the quarter is the end-of-sample residual from that linear time trend regression. Thus, to compute the complete linear trend output gap series, I estimate 40 time trend regressions over the decade under review.

An alternative approach to estimating the real-time output gap is to estimate a HodrickPrescott (HP) filter. Indeed, this approach has been taken by Taylor (1999b) and Perez (2001) to estimate output gaps over the 1970s. ${ }^{10}$ A potential problem with this approach is that it is unlikely to approximate the approach taken by policy authorities during the 1970s since the original working paper by Hodrick and Prescott did not begin circulating until 1981. ${ }^{11}$ Consequently, it seems more realistic to assume that a deterministic linear time trend model is a better approximation to actual real-time estimates of potential output during the 1970s

Figure 1 shows that both real-time output gap estimates are generally below the revised CBO estimate of the output gap although the CEA gap is always lower than the gap generated from linear trends. Indeed, the CEA gap is negative over the entire decade. Consequently, using either of these series and following a Taylor rule in real time would have generated a policy that produced federal fund rates that were too low when compared to outcomes based on revised data. For example, in 1975, the CEA real-time estimate of the output gap reached about -16 percent while the revised estimate of the output gap is only -4 percent. Consequently, using this estimate of the output gap and following the parameterized Taylor rule in real time during 1975 would have resulted in setting the federal funds rate about six percentage points too low, a rather large mistake. The outcome for the linear trend gap is somewhat better but still systematically biased. In 1975, this estimate of the gap would have led to a target federal funds rate that was about 2.5 percentage points too low relative to the value obtained using the revised estimate of the output gap. It is also troubling to note that even the sign of these real-time output gap measures is "wrong" over much of this period, especially for the CEA estimate.

In this paper, I examine four simple approaches to addressing this problem of failure to observe the output gap in real time. Each involves replacing the true value of the output gap, $y_{t}$,

\footnotetext{
6 The productivity slowdown that began in the early 1970s has been widely investigated. See, for example, "Symposium: The Slowdown in Productivity Growth," Journal of Economic Perspectives, vol. 2, Fall 1988, 3-98.

7 The CBO reports potential estimates potential output at an annual frequency. I obtain quarterly estimates by loglinear interpolation.

8 I am grateful to Athanasios Orphanides for generously sharing these data with me.

9 This is the approach taken by Mehra (2002). Taylor (1993) also estimates a linear time trend to obtain the output gap; however, he uses a single two-sided trend based on revised (1993) data.

${ }_{10}$ Taylor (1999b) uses revised data to estimate a two-sided filter while Perez (2001) estimates a sequence of one-

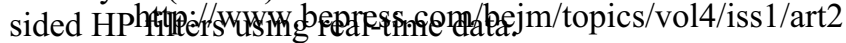

11 The paper has since been published: Hodrick and Prescott (1997).
} 


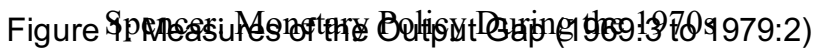

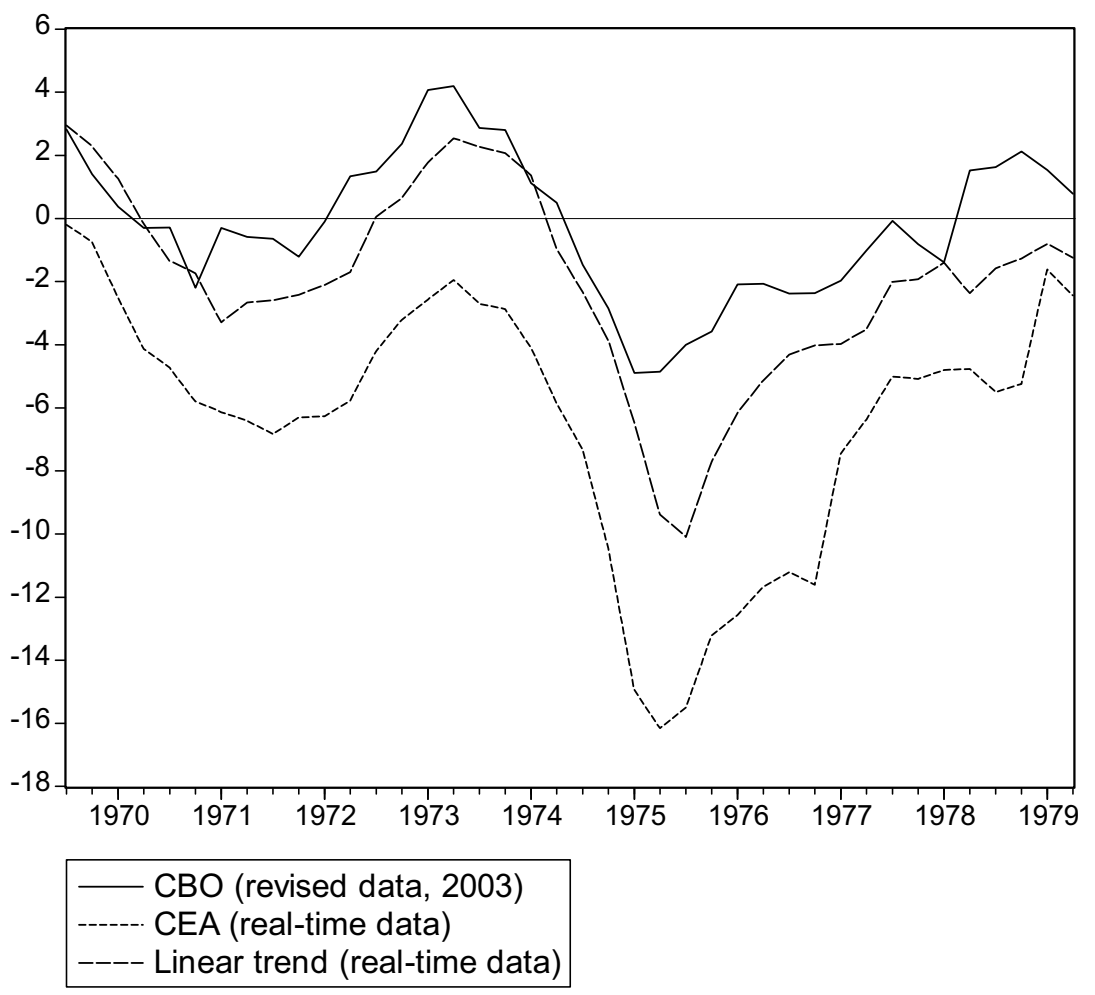

with a noisy proxy available in real time. I introduce these proxies in the next section and explore the impact each might have had during the 1970s in Section IV.

\section{Real-Time Monetary Policy Rules}

For purposes of evaluation, I maintain the working assumption that the Taylor parameterization of equation (1) represents a useful policy benchmark if it is implemented with ideal data. These ideal data include revised ("final") measures of the contemporaneous rate of inflation and the contemporaneous output gap. Accordingly, although this rule with these data could not have been implemented in real time, it gives the ideal against which I will compare alternative attainable real-time rules. Consequently, in order for the results of the paper to be persuasive, it is important to accept the claim that a full-information Taylor rule generates good policy outcomes. This claim is consistent with much of the recent work by both academic economists and central bankers. For example, the Federal Bank of St. Louis plots the implications of the Taylor rule as a policy benchmark in its monthly publication, Monetary Trends. Taylor (1999b) employs an approach similar to the one used here and calls it "historical 'policy mistake' analysis" (p. 336). In his comment on that paper, Richard Clarida states, "Now if, as we have learned from the central bankers present at this conference, the Taylor rule can be and is used as a benchmark for assessing the current stance of actual monetary policies, then certainly it can also be used as part of a framework to interpret monetary history." (Taylor (1999a), p. 342) A consensus seems to have arisen that Taylor-type rules are not only generally descriptive of how the Fed has operated, at least since 1987, but also prescriptive: a Taylor rule is approximately Published by The Berkeley Electronic Press, 2004 
optimal. $^{12}$

Topics in Macroeconomics, Vol. 4 [2004], Iss. 1, Art. 2

Actual policy differs from this idealized rule in two important ways: (1) Policymakers must respond to preliminary real-time, not revised, data. (2) Policymakers cannot observe the contemporaneous (current) values of inflation and output; even preliminary data are only available with lags. So, while policymakers must make interest rate decisions using real-time data subject to error and only measured with lags, the policy goal is to attain, at any point in time, the target federal funds rate path that would result under full information implementation of the ideal rule. Success in achieving the goal can only be evaluated years after the actual event.

The operational real-time Taylor rule is given by

(1') $i_{t}^{R}=\alpha+\beta\left(\pi_{t}^{R}-\pi^{*}\right)+\gamma p_{t}^{R}$

where $\pi_{t}^{R}$ is the real-time observation on the rate of inflation, $p_{t}^{R}$ is one of the four real-time proxies for the output gap to be discussed below, and $i_{t}^{R}$ is the resulting target value of the federal funds rate using real-time data. The policy error can be expressed as the difference between the ideal outcome for the federal funds rate implied by equation (1) and the real-time outcome implied by equation (1'):

(2) $i_{t}-i_{t}^{R}=\beta\left(\pi_{t}-\pi_{t}^{R}\right)+\gamma\left(y_{t}-p_{t}^{R}\right)$

The first term in this error equation is likely to be much less important than the second. ${ }^{13}$ Consequently, the principal obstacle to conducting ideal policy is real-time error in the measurement of the output gap.

In view of the inability to accurately observe the contemporary output gap, I consider four alternative real-time proxy candidates for $y_{t}$ which I then use in applying the operational Taylor rule given by equation (1'). Each is a noisy estimate of $y_{t}$ and will yield different counterfactual outcomes for the path of the federal funds rate.

The first noisy proxy candidate for the true but unobserved output gap is the actual real-time estimate of the output gap used by Orphanides and shown in Figure 1 above - the CEA output gap. I denote this real-time estimate of the output gap by $\hat{y}_{t}$ and the observation error by $\eta_{t}$. Thus, $y_{t}=\hat{y}_{t}+\eta_{t}$ and, substituting the proxy into equation ( $\left.1^{\prime}\right)$, the actual rule becomes

(A) $i_{t}^{R}=\alpha+\beta\left(\pi_{t}^{R}-\pi^{*}\right)+\gamma \hat{y}_{t}=\alpha+\beta\left(\pi_{t}-\pi^{*}\right)+\gamma y_{t}+\left[\beta\left(\pi_{t}-\pi_{t}^{R}\right)-\gamma \eta_{t}\right]$

As illustrated by the second equality, if this rule were followed, the (ex post) policy "mistake" is to increase the federal funds rate by $\left[\beta\left(\pi_{t}-\pi_{t}^{R}\right)-\gamma \eta_{t}\right]$ more than the full information Taylor

12 This emerging consensus is discussed in more detail by McCallum (1999). See also the papers in the Taylor (1999a) conference volume from a broad array of monetary economists and the recent survey paper by Clarida, Gali, and Gertler (1999). Regarding the approximate optimality of Taylor-type rules, see Rotemberg and Woodford (1999), Clarida, Gali, and Gertler (1999), and Woodford (2001). It is also interesting to note the characterization of the Taylor rule in a statement by then Federal Reserve Governor Janet Yellen at the January 1995 meeting of the FOMC: "It seems to me that a reaction function in which the real funds rate changes by roughly equal amounts in response to deviations of inflation from a target of 2 percent and to deviations of actual from potential output describes reasonably well what this committee has done since 1986 . ... If we wanted a rule, I think the Greenspan Fed has done very well following such a rule, and I think that is what sensible central banks do."

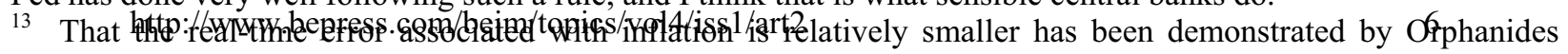
(2000, 2000b ). See also Mehra (2002). 


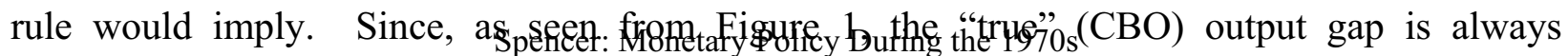
considerably greater than this real-time estimate over the $1970 \mathrm{~s}, \eta_{t}$ is always positive. Consequently, if, as I presume, $\beta\left(\pi_{t}-\pi_{t}^{R}\right)$ is small, the federal funds rate will be consistently lower than would have been achieved by a Taylor rule applied using the correct output gap.

The second proxy is the real-time estimate of the output gap obtained as the residual from a one-sided linear time trend, also shown in Figure 1. This real-time estimate of the output gap is constructed as described above using real-time output data available in period $t$ and is denoted by $\hat{y}_{t}^{T}$. The observation error is denoted by $\varepsilon_{t}$. Consequently, $y_{t}=\hat{y}_{t}^{T}+\varepsilon_{t}$ and so the actual rule becomes

$$
i_{t}^{R}=\alpha+\beta\left(\pi_{t}^{R}-\pi^{*}\right)+\gamma \hat{y}_{t}^{T}=\alpha+\beta\left(\pi_{t}-\pi^{*}\right)+\gamma y_{t}+\left[\beta\left(\pi_{t}-\pi_{t}^{R}\right)-\gamma \varepsilon_{t}\right]
$$

If this rule were followed, the (ex post) policy "mistake" is to increase the federal funds rate by $\left[\beta\left(\pi_{t}-\pi_{t}^{R}\right)-\gamma \varepsilon_{t}\right]$ more than implied by the full information Taylor rule.

The third approach takes the steady state value of the output gap of zero as a first approximation to the true output gap in the face of considerable uncertainty. Thus, the observation error is the true output gap itself, $y_{t}$. The potential merit of this proxy relative to the previous real-time output gap estimates, especially for the $1970 \mathrm{~s}$, is suggested by the results shown in Figure 1; the real-time estimates of the output gap frequently fail to even get the sign right. For this proxy, actual policy will respond only to inflation movements since the rule becomes

(C) $i_{t}^{R}=\alpha+\beta\left(\pi_{t}^{R}-\pi^{*}\right)+\gamma \cdot 0=\alpha+\beta\left(\pi_{t}-\pi^{*}\right)+\gamma y_{t}+\left[\beta\left(\pi_{t}-\pi_{t}^{R}\right)-\gamma y_{t}\right]$

Under Rule $\mathrm{C}$, the policy mistake is that the federal funds rate will be higher than implied by the full information Taylor rule by $\left[\beta\left(\pi_{t}-\pi_{t}^{R}\right)-\gamma y_{t}\right]$.

The fourth and final proxy for the output gap is obtained from a Phillips curve expression. ${ }^{14}$ A common representation of the Phillips curve is given by

$$
\pi_{t}=\lambda E_{t} \pi_{t+1}+(1-\lambda) \pi_{t-1}+\mu y_{t}+e_{t}
$$

where $E_{t} \pi_{t+1}$ is the (rational) expectation at time $t$ of inflation in period $t+1$ and $e_{t}$ is a random disturbance. Solving this equation for the output gap gives

$$
y_{t}=(1 / \mu) \Delta \pi_{t}-(\lambda / \mu)\left(E_{t} \pi_{t+1}-\pi_{t-1}\right)-(1 / \mu) e_{t}
$$

Consequently, $(1 / \mu) \Delta \pi_{t}$ could serve as a noisy proxy for the output gap ${ }^{15}$ except that the actual change in the rate of inflation is not observed in real time. The real-time counterpart and the final proxy candidate is, thus, $(1 / \mu) \Delta \pi_{t}^{R}$. With this proxy, the observation error for the output gap is

14 This approach is also examined by Leitemo and Lonning (2002), though not in a real-time context.

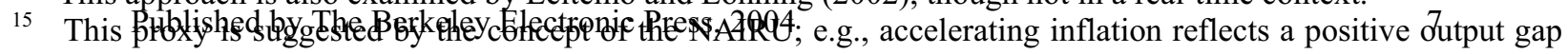
(negative unemployment gap) with the magnitudes being approximately proportional. 


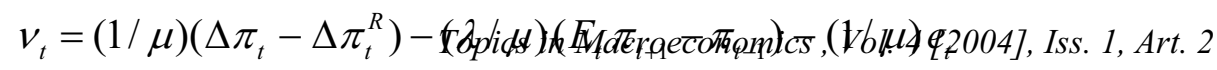

Thus, the actual policy rule becomes

(D) $i_{t}^{R}=\alpha+\beta\left(\pi_{t}^{R}-\pi^{*}\right)+(\gamma / \mu) \Delta \pi_{t}^{R}=\alpha+\beta\left(\pi_{t}-\pi^{*}\right)+\gamma y_{t}+\left[\beta\left(\pi_{t}-\pi_{t}^{R}\right)-\gamma v_{t}\right]$

Under policy Rule $\mathrm{D}$, the mistake will be that the federal funds rate will be higher than the value implied by the full information Taylor rule by $\left[\beta\left(\pi_{t}-\pi_{t}^{R}\right)-\gamma \nu_{t}\right]$.

Any preference for one of these rules over the others in practice would depend on the relative magnitudes of the respective observation errors associated with each output gap proxy: $\eta_{t}, \varepsilon_{t}, y_{t}$, and $v_{t}$. For example, suppose that the errors in the CEA output gap, $\eta_{t}$, are systematically larger than the actual output gap itself, $y_{t}$. In such a case, it would be less misleading to ignore this measured output gap in real time altogether, as in Rule $\mathrm{C}$, than to follow Rule A.

One way to assess the relative noisiness of each of these proxies is to compute and compare their root mean square errors (RMSEs). In each case, the RMSE is computed by

$$
\left[\frac{1}{40} \sum_{t=1969: 3}^{1979: 2}\left(p_{t}^{R}-y_{t}\right)^{2}\right]^{\frac{1}{2}}
$$

where, as before, $p_{t}^{R}$ represents the respective real-time proxy for the output gap and $y_{t}$ is the CBO estimate of the output gap as of 2003 which we take as giving "true" values. The results are reported in Table 2. ${ }^{16}$ The largest RMSE belongs to the CEA output gap used in Rule A while the smallest RMSE, perhaps surprisingly, belongs to the zero (steady state) estimate of Rule C. This suggests that ignoring real-time information about the output gap may have been a good strategy for policy during the 1970s.

Further insight regarding the relative performance of these alternative proxies can be obtained by comparing implied paths of the federal funds rate over the 1970s under each of the four real-time policy rules discussed above with the actual path of the federal funds rate and the path implied by the Taylor rule using fully revised data. This is undertaken in the next section.

\section{Comparing Alternative Rules}

As a baseline for the analysis to follow, Figure 2 shows the actual time path for the federal funds rate over 1969:3-1979:2 as well as the time path prescribed by the ideal parameterized Taylor rule using revised data available in 2002. Under the assumption that this full information Taylor rule yields good policy outcomes, these results confirm the consensus view that monetary policy

16 I have also investigated two other approaches in the spirit of Rule B. I have estimated the trend by a rolling linear trend of length 15 years and also by a 15-year one-sided HP filter (even though, as mentioned above, the HP filter had not yet been popularized by the 1970s). The RMSE for the rolling linear trend is 3.14 which is worse that for the linear trend with a constant starting date of 1953:1. Consequently, I will retain the measure in Rule B. The RMSE for the HP filter is 2.02 which is better than any other real time measure of the output gap. However, given doubts that policymakers could have replicated the HP filter in the 1970s before it was popularized in the 1980s, I

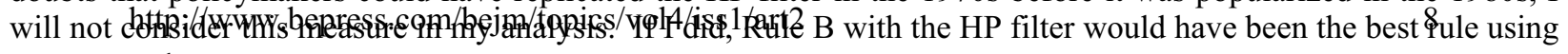
my approach. 
Spencer: Monetary Policy During the 1970s

\section{Table 2: Root Mean Square Error (RMSE) for Output Gap Proxies}

\begin{tabular}{lcc}
\hline Output gap proxy $^{\mathrm{a}}$ & Error $^{\mathrm{a}}$ & $\begin{array}{c}\text { Computed RMSE } \\
(1969: 3-1979: 2)\end{array}$ \\
\hline $\mathrm{A}: \hat{y}_{t}$ & $\eta_{t}$ & 6.63 \\
$\mathrm{~B}: \hat{y}_{t}^{T}$ & $\varepsilon_{t}$ & 2.37 \\
$\mathrm{C}: 0$ & $y_{t}$ & 2.27 \\
$\mathrm{D}:(1 / \mu) \Delta \pi_{t}^{R}$ & $v_{t}$ & 4.46
\end{tabular}

${ }^{\mathrm{a}}$ For definitions, see the text.

Figure 2: Federal Funds Rate (1969:3 to 1979:2)

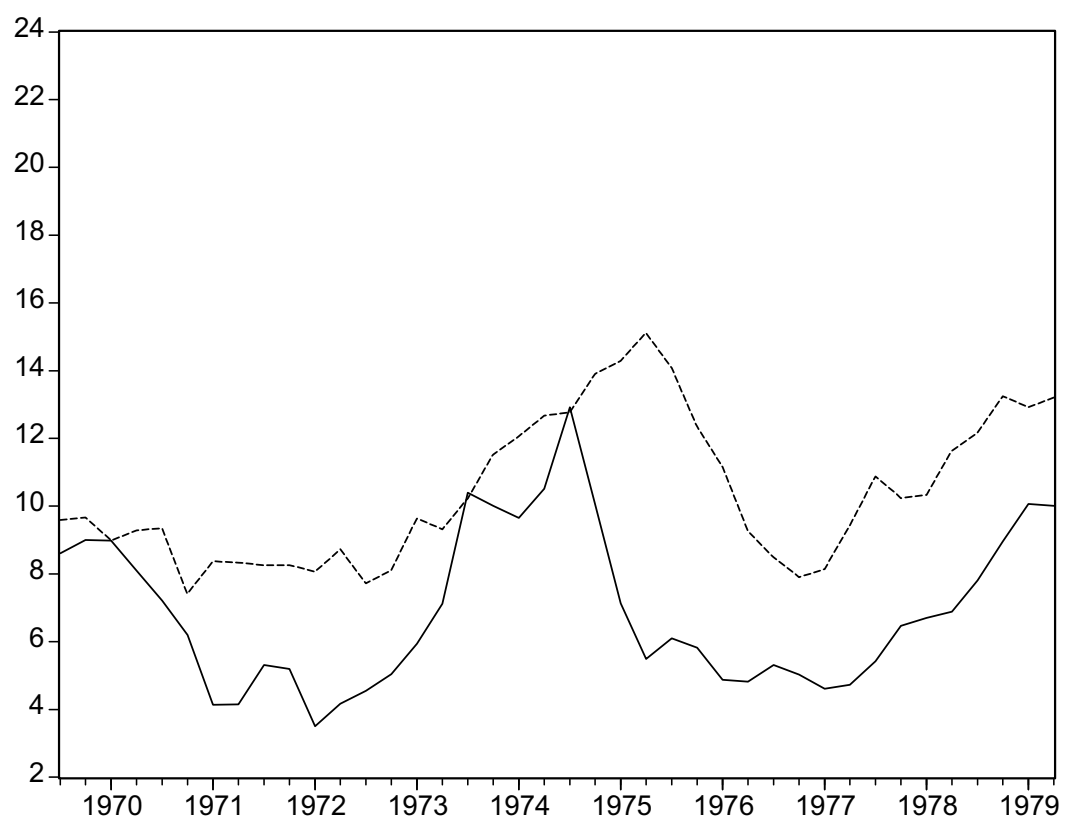

- Actual federal funds rate
---- Federal Funds rate implied by Taylor rule (revised data) 


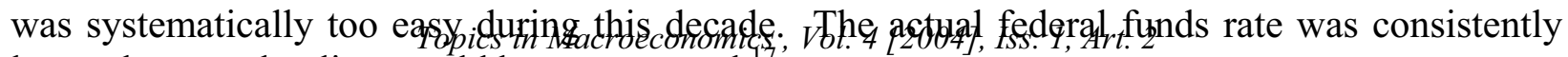
lower than good policy would have suggested.

Each of the four rules presented in the previous section replaces the "true" output gap presumed in the ideal Taylor rule with a real-time noisy proxy. In this sense, each is intended to be a real-time approximation to this ideal rule. If any proxy is error free, the corresponding rule collapses to the ideal Taylor rule and the implied path for the federal funds rate will be as in Figure 2. In what follows, I ask how the time path of the federal funds rate implied by each of the real-time rules introduced in the previous section compares with the actual path of the federal funds rate and the benchmark path implied by the Taylor rule using fully revised data. ${ }^{18}$ In each case, the rate of inflation is the real-time counterpart of the estimates used by Taylor: the average over the most recent four quarters using the Croushore and Stark (2001) data.

Rule A uses the real-time CEA estimates of the output gap as the proxy for the unobserved true output gap. The parameterized rule ${ }^{19}$ is given by

$$
i_{t}^{R}=1.0+1.5 \pi_{t}^{R}+0.5 \hat{y}_{t}
$$

Using real-time data for both the output gap and the inflation rate, Figure 3 plots the path for the federal funds rate following this rule along with the actual path and the final data Taylor rule path carried over from Figure 2. Note that, on a point-by-point basis, this rule comes close to replicating the actual behavior of the federal funds rate over this period. ${ }^{20}$ This is consistent with the claim made by Orphanides (2002a, p. 118) that the "real-time [Taylor] rule yields policy very similar to that actually pursued. Thus, had this policy rule been followed during the 1970s, economic outcomes would likely have been similar to the actual history." This result suggests that, at least during this decade, using the CEA real-time output gap measures would probably not have significantly improved policy performance.

Parameterized Rule B employs the real-time linear trend gap and is given by

$$
i_{t}^{R}=1.0+1.5 \pi_{t}^{R}+0.5 \hat{y}_{t}^{T}
$$

where the construction of the output gap series has been described above. The implied point-bypoint path for the federal funds rate is compared with the actual and ideal paths in Figure 4. Given that this proxy is a uniformly better estimate of the actual output gap than the CEA output gap, it is not surprising to see that Rule B does better than Rule A. The Rule B time path for the federal funds rate reflects a policy that is less accommodative than the actual policy for virtually the entire decade although it remains generally more accommodative than the ideal policy. The conclusion, then, is that following a Taylor rule with a linear trend estimate of the output gap

17 Note that if the Fed had followed this idealized rule over the full sample period, the paths for inflation and the output gap would have been different implying different policy outcomes for the federal funds rate. Since I use historical data for inflation and the output gap (or its proxies), the resulting counterfactual paths for the federal funds rate (both here and below) should not be interpreted as time series and thus directly comparable to the actual time series for the federal funds rate. Rather, they must be interpreted on a point-by-point basis: at each date, could the Fed have done better? This is the same approach taken by Taylor (1999b; see his Figures 7.4-7.6) and Orphanides (2002a; see his Figure 3).

18 Once again, the counterfactual federal funds rate paths are not what would have arisen if the Fed had followed the corresponding rule for the entire period. See the previous footnote. Since each of the counterfactual paths has the same interpretation, however, they can be compared with each other over the entire period under investigation.

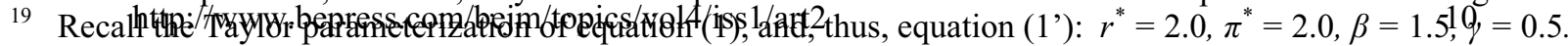

20 For the reasons mentioned in footnote 17 above, this does not imply that the Fed followed this rule. 


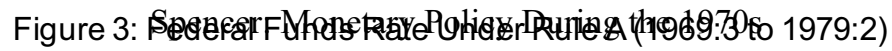

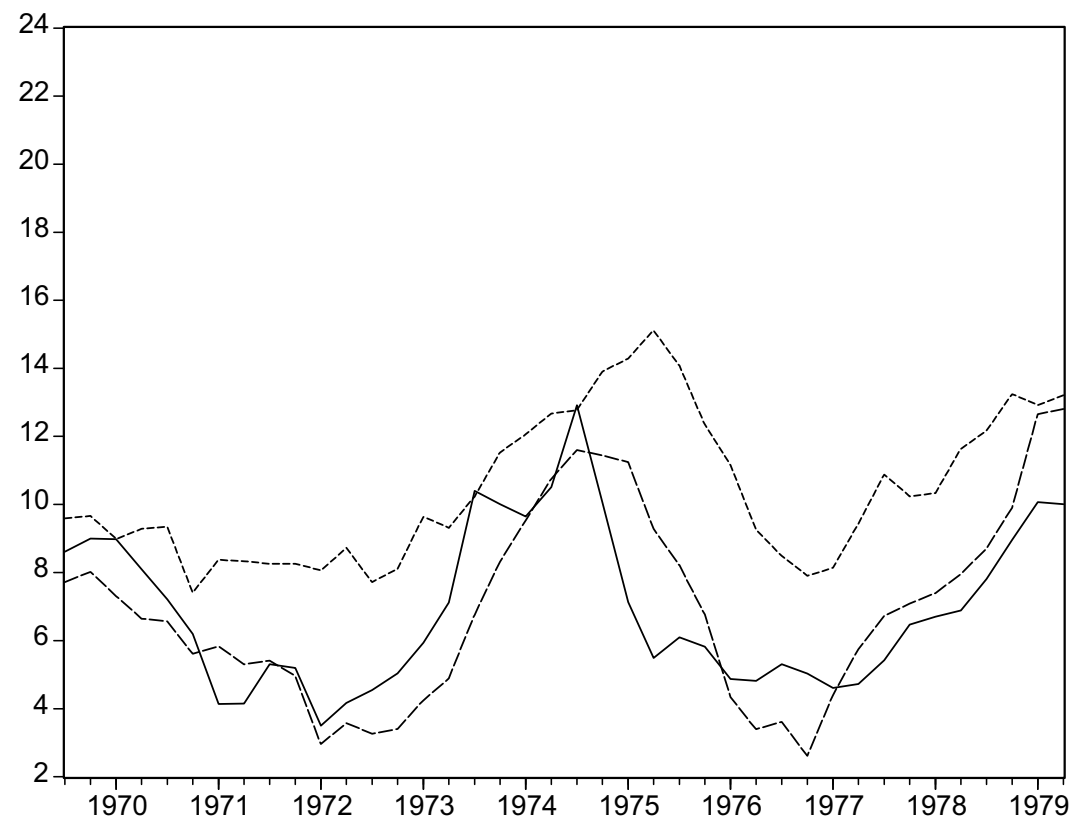

- Actual federal funds rate

----. Taylor rule (revised data)

---- Rule A (real-time data)

Figure 4: Federal Funds Rate Under Rule B (1969:3 to 1979:2)

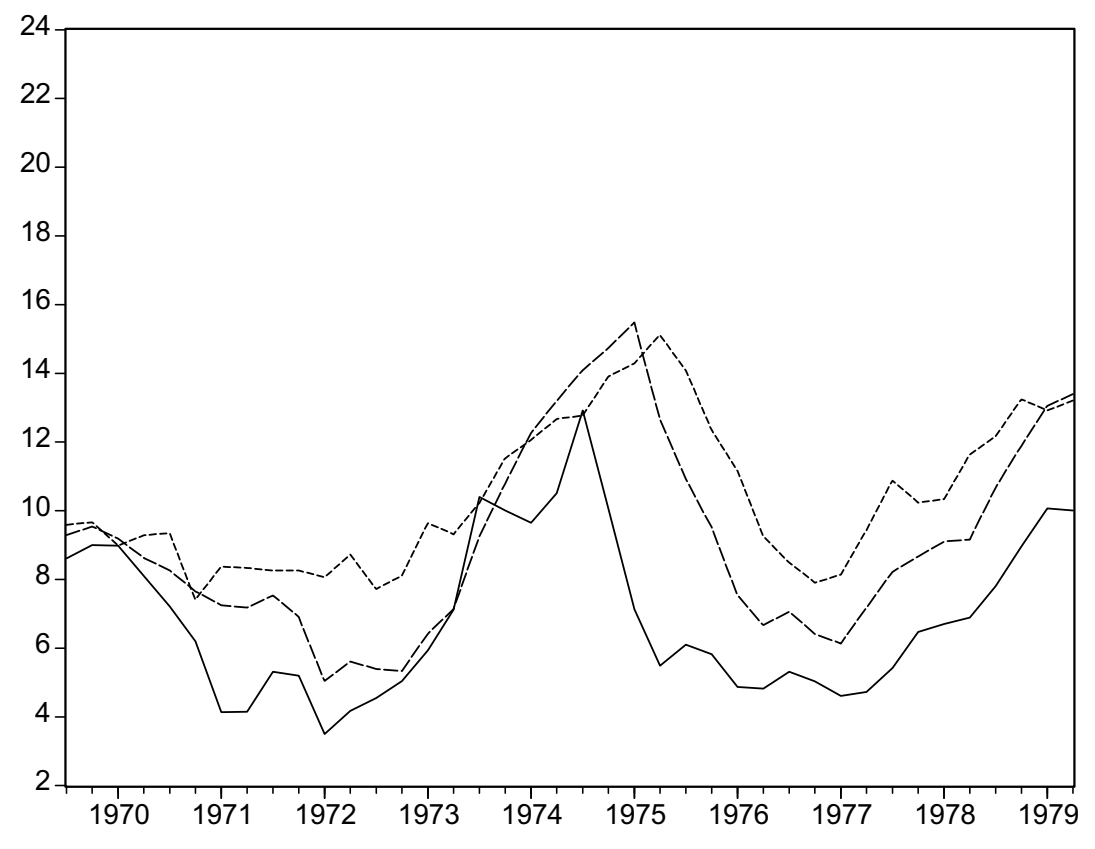

- Actual federal funds rate

---.- Taylor rule (revised data)

---- Rule B (real-time data)

Published by The Berkeley Electronic Press, 2004 


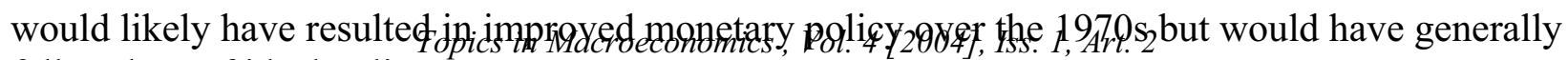
fallen short of ideal policy.

Next, consider Rule C which uses as proxy for the unobserved output gap its steady state value of zero. This is equivalent to giving a zero weight to any estimate of the output gap. The parameterized Rule $\mathrm{C}$ is given by

(6) $i_{t}^{R}=1.0+1.5 \pi_{t}^{R}$

where the rate of inflation is, once again, measured using real time data. The path for the federal funds rate implied by this rule is shown in Figure 5. The results for Rule $\mathrm{C}$ are considerably more encouraging than those for Rule A and comparable to the results for Rule B. We observe that the federal funds rate implied by the rule generally suggests a tighter policy than actually pursued. Indeed over much of the decade, it approximates the outcome from the ideal Taylor rule fairly well. At no point does it imply a policy that is significantly more accommodative than the policy actually pursued. Thus, we conclude that Rule $\mathrm{C}$ appears to be slightly better than Rule B and clearly superior to Rule A as well as to actual policy over the decade under investigation. This may seem surprising since Rule $\mathrm{C}$ is equivalent to ignoring any real-time information on the output gap; i.e., during the 1970s, real-time information regarding short-run behavior of the output gap appears to have been worse than no information at all.

Finally, Rule D employs changes in the rate of inflation as a proxy for the unobserved output gap. Referring to equation (D) above, we see that parameterization requires not only asserting a value for $\gamma$, which we take from the Taylor rule to be 0.5 , but also the parameter $\mu$ from the Phillips curve equation (3). I take the value for $\mu$ to be 0.15 , the value assumed by Judd and Rudebusch $(1998)^{21}$ in their model used to evaluate alternative policy rules. Thus, the parameterized Rule D is given by

(7) $i_{t}^{R}=1.0+1.5 \pi_{t}^{R}+3.33 \Delta \pi_{t}^{R}$

where the inflation rate and its change are measured in real time. The implied path for the federal funds rate is reported in Figure 6.

There are three interesting characteristics of the federal funds rate implied by Rule D. First, it is generally less accommodative than the actual federal funds rate path. Second, it fluctuates about the ideal path. These characteristics are encouraging. The third characteristic is less so: the implied path is quite irregular and jagged.

Such irregularity suggests investigating the impact of interest rate smoothing. There is considerable evidence that the Fed does smooth interest rates; see e.g., Levin, Wieland, and Williams (1999), Clarida, Gali, and Gertler (2000), Sack and Wieland (2000), and Orphanides (2002a). ${ }^{22}$ To capture interest rate smoothing, begin by rewriting Rule D as

(D') $i_{t}^{R^{*}}=\alpha+\beta\left(\pi_{t}^{R}-\pi^{*}\right)+(\gamma / \mu) \Delta \pi_{t}^{R}$

21 See equation (5) in Judd and Rudebusch (1998), p. 11.

22 Rudebusch (2002) offers indirect evidence that apparent policy inertia reflects the persistence of shocks rather than explicit interest rate smoothing, at least over the late 1980s and the 1990s; his sample does not include the 1970s. Mehra (2002) considers this issue and finds stronger evidence of interest rate smoothing over the earlier

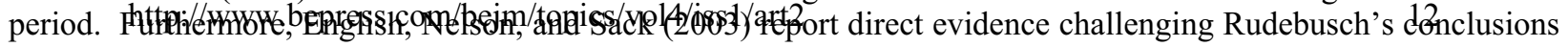
over his sample period. 


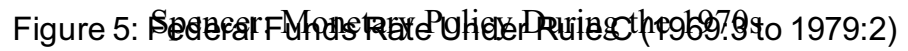

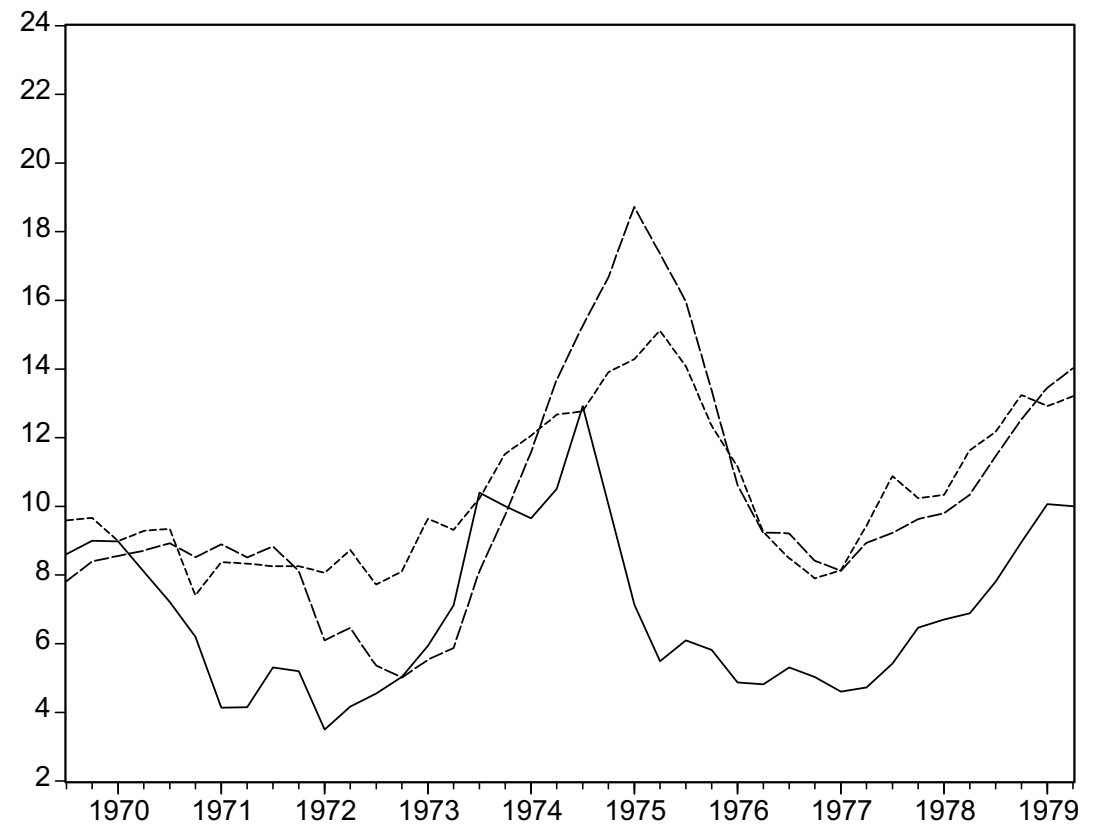

Actual federal funds rate

----. Taylor rule (revised data)

Figure 6: Federal Funds Rate Under Rule D (1969:3 to 1979:2)

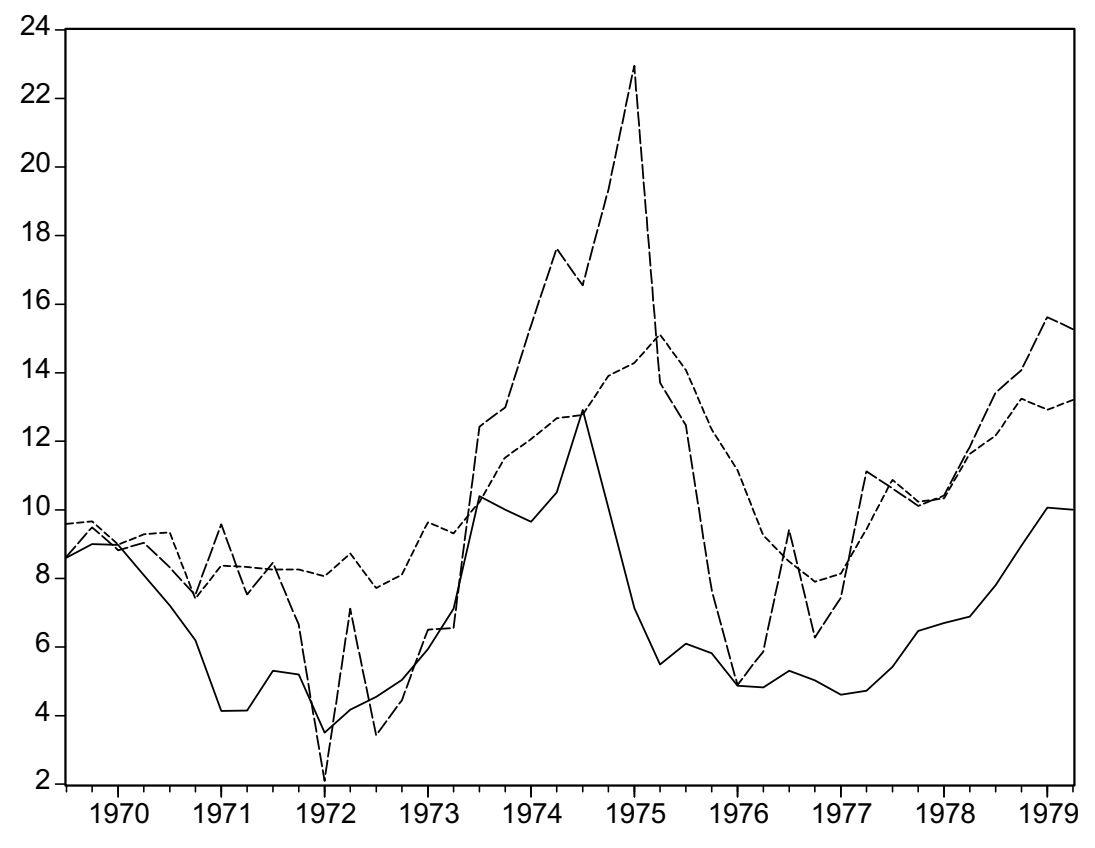

Actual federal funds rate

Taylor rule (revised data)

Rule D (real-time data)

Published by The Berkeley Electronic Press, 2004 


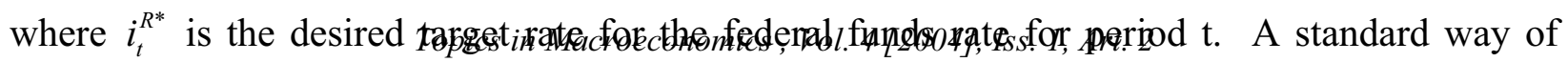
representing interest rate smoothing behavior is to postulate a partial adjustment model in which the actual interest rate change is a fraction, $1-\rho$, of the desired change:

$$
i_{t}^{R}-i_{t-1}^{R}=(1-\rho)\left(i_{t}^{R^{*}}-i_{t-1}^{R}\right) \quad ; \quad 0 \leq \rho<1
$$

Thus, $\rho$ is a measure of policy inertia or interest rate smoothing. Plugging (D') into (8) and solving for $i_{t}^{R}$ gives

$$
i_{t}^{R}=(1-\rho)\left[\alpha+\beta\left(\pi_{t}^{R}-\pi^{*}\right)+(\gamma / \mu) \Delta \pi_{t}^{R}\right]+\rho i_{t-1}^{R}
$$

Estimates of $\rho$, the interest rate smoothing parameter over the 1970s have varied. Clarida, Gali, and Gertler estimate a value of 0.7 to 0.8 while Orphanides (2002a) reports an estimate of about 0.6 and Mehra (2002) an estimate of 0.44. Of course, studies that do not allow for interest rate smoothing implicitly assume a value of 0.0 . To investigate the consequences of smoothing, I take the intermediate value of 0.5 to give a sense of the implications of interest rate smoothing. Thus, the parameterized smoothed Rule D is

(10) $i_{t}^{R}=0.5\left[1.0+1.5 \pi_{t}^{R}+3.33 \Delta \pi_{t}^{R}\right]+0.5 i_{t-1}^{R}$

The results for this smoothed version of Rule D are reported in Figure 7. The implied path for the federal funds rate looks similar to the path implied by Rule $C$ and shown in Figure 5. Consequently, it appears that using the real-time change in the rate of inflation as a proxy for the unobserved output gap would have resulted in a policy outcome that is superior to actual policy. Under interest rate smoothing, the implied path is not a bad approximation of the policy suggested by the full-information Taylor rule.

A final assessment of the ability of the alternative paths for the federal funds rate to track the ideal path is obtained by computing root mean square deviations (RMSDs) from the ideal path over 1969:3-1979:2. This RMSD is computed by

$$
\left[\frac{1}{40} \sum_{t=1969: 3}^{1979: 2}\left(i_{t}-i_{t}^{*}\right)^{2}\right]^{\frac{1}{2}}
$$

where $i_{t}^{*}$ is the ideal federal funds rate generated by the full information Taylor rule and $i_{t}$ is a placeholder for the actual federal funds rate and the federal funds rates implied by each of the five policy rules under consideration. The results are reported in Table 3. Several observations are notable. First, given the results of Table 2, we are not surprised at the relative ranking of Rules A-D. It is interesting to note, however, that the Rule A, using the CEA output gap measure, improves slightly upon actual policy behavior. We also confirm the observation from Figure 7 that smoothing Rule D improves the performance of that rule considerably. We also see that, overall, Rule $\mathrm{C}$ comes the closest to fitting the ideal policy rule although only slightly more closely than Rule B. Once again, we arrive at the conclusion that the performance of monetary

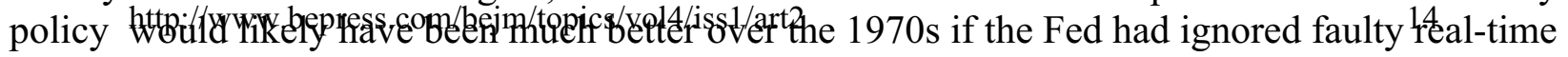




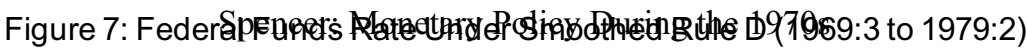

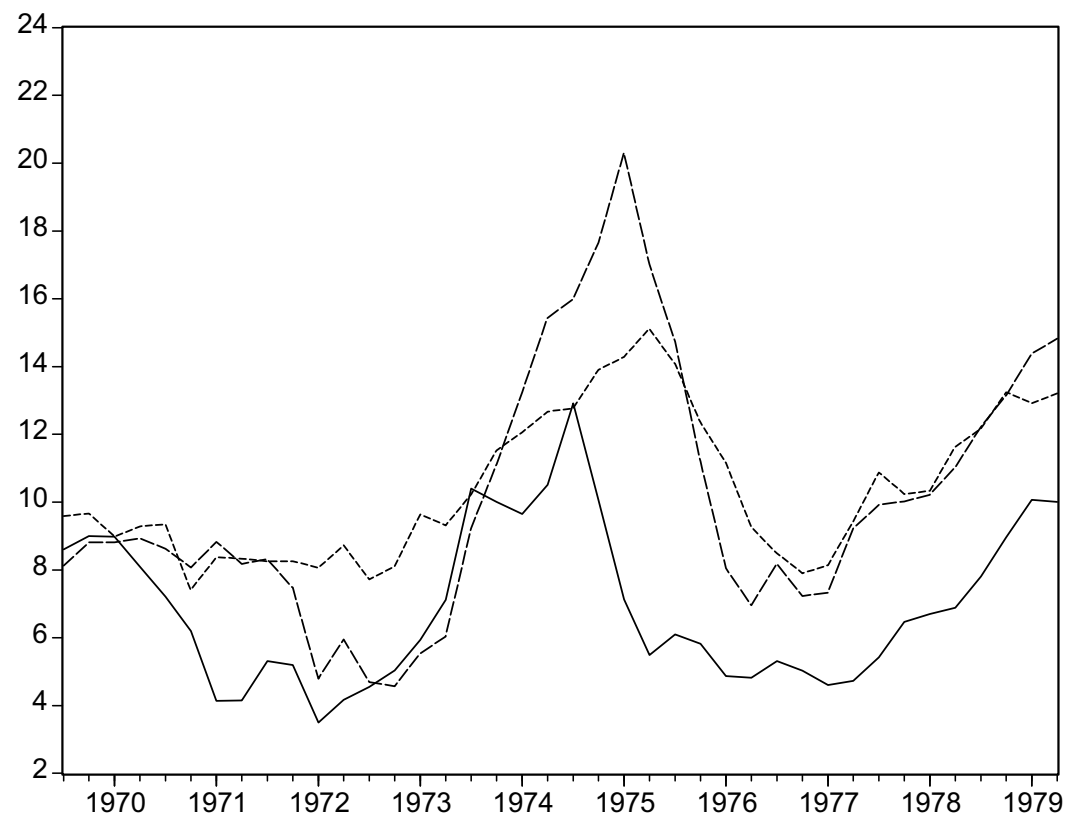

- Actual federal funds rate

-----. Taylor rule (revised data)

---- Smoothed rule D (real-time data)

Table 3: Root Mean Square Deviation (RMSD) for Federal Funds Rate Paths

Federal Funds Rate Path ${ }^{\mathrm{a}}$

Computed RMSD

(1969:3-1979:2)

Actual path

4.08

Path implied by Rule A

Path implied by Rule B

1.86

Path implied by Rule C

Path implied by Rule D

Path implied by smoothed Rule D

${ }^{\mathrm{a}}$ For definitions, see the text. 


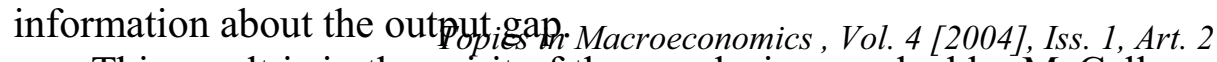

This result is in the spirit of the conclusion reached by McCallum (2001). He examines the outcome for inflation and output variability of using a Taylor-type rule when the output gap is measured with error. His results (see his Table 3) suggest that, under such circumstances, superior results are achieved by reducing the responsiveness of monetary policy to the measured output gap. Indeed, for the parameter values he considers, the value of $\gamma$ (his $\mu_{2}$ ) that gives the best outcomes is $\gamma=0.0$. This is the same as Rule C.

\section{Conclusion}

This paper has explored the failure of monetary policy in the 1970s in the U.S. The results support the conclusion that a significant reason for this failure was that the Fed responded to severely misperceived and systematically biased assessments of the state of the economy. It appears in retrospect that real-time perceptions were much more pessimistic than turned out to be true. Consequently, the Fed pursued policy that, though intended to be appropriate, turned out to accommodate inflation.

In view of the inability of the Fed to accurately observe the output gap in real time, this paper has proffered four alternative proxies for the output gap that could have been observed in real time. Two of these proxies are real-time estimates of the output gap. The first of these is taken from estimates produced by the Council of Economic Advisors. The second is based on a real-time linear time trend. A third proxy takes the steady state output gap value of zero as a first approximation to its true value at any point in time. The fourth proxy exploits the Phillips curve relationship and posits the real-time measure of the change in the rate of inflation as a possible indicator of movements in the true output gap.

Each of these real-time proxies was implemented using the Taylor rule to generate counterfactual (point-by-point) paths for the federal funds rate over the 1970s. These paths were compared to the actual historical path of the federal funds rate which reflects failed policy and to the counterfactual path implied by an ideal full-information Taylor rule. While each of these real-time proxies generated better outcomes than actually occurred, there were important differences. The improvement was only slight when the real-time CEA output gap estimates were used. The other three real-time output gap measures offered considerable improvement. Perhaps the most surprising result is that the best outcome is obtained by the third proxy which assumes an output gap of zero. Thus, the results suggest that the Fed could have done much better if it had avoided considering real-time direct estimates of the output gap and only responded to movements in the observed rate of inflation.

I have focused on the decade of the 1970s because of the particularly high level of uncertainty regarding the behavior of potential output and thus the output gap during that period. But, the results reported here may be valuable when considering other eras of increased uncertainty regarding the behavior of potential output such as occurred in the U.S. in the late 1990s. Casual empiricism suggests that during this period, the Federal Reserve attenuated its policy response to real-time estimates of an increasing output gap in the face of uncertainty about the growth rate of potential output. Investigation of these issues is the subject of research in progress. 
Clarida, Richard, Jordi Gali, and Mark Gertler. "The Science of Monetary Policy: A New Keynesian Perspective.” Journal of Economic Literature, December 1999, 37(4), pp. 16611701.

-, - , and - "Monetary Policy Rules and Macroeconomic Stability: Evidence and Some Theory." Quarterly Journal of Economics, February 2000, 115(1), pp. 147-80.

Croushore, Dean and Stark, Tom. "A Real-Time Data Set for Macroeconomists." Journal of Econometrics, November 2001, 105(1), pp. 111-130.

English, William B., William R. Nelson, and Brian P. Sack. "Interpreting the Significance of the Lagged Interest Rate in Estimated Monetary Policy Rules." Contributions to Macroeconomics, 2003, 3(1), Article 5. http://www.bepress.com/bejm/contributions/vol3/iss1/art5

Hodrick, Robert J. and Edward C. Prescott. "Postwar U.S. Business Cycles: An Empirical Investigation." Journal of Money, Credit and Banking, February 1997, 29(1), pp. 1-16.

Judd, John F. and Glenn D. Rudebusch. "Taylor's Rule and the Fed: 1970-1997." Federal Reserve Bank of San Francisco Economic Review, 1998, Number 3, pp. 3-16.

Leitemo, Kai and Ingunn Lonning. "Simple Monetary Policymaking without the Output Gap." Norges Bank (Oslo, Norway) Working Paper, October 2002.

Levin, Andrew; Volker Wieland, and John C. Williams. "Robustness of Simple Monetary Policy Rules under Model Uncertainty," in Taylor (1999a), 1999, pp. 263-99.

McCallum, Bennett T. "Recent Developments in the Analysis of Monetary Policy Rules." Federal Reserve Bank of St. Louis Review, November/December 1999, pp. 3-12.

-. "Should Monetary Policy Respond Strongly to Output Gaps?" American Economic Review, May 2001, 91(2), pp. 258-262.

Mehra, Yash P. "The Taylor Principle, Interest Rate Smoothing and Fed Policy in the 1970s and 1980s." Federal Reserve Bank of Richmond Working Paper, August 2002.

Orphanides, Athanasios. "The Quest for Prosperity without Inflation." European Central Bank (Frankfurt, Germany) Working Paper No. 15, March 2000.

- "Monetary Policy Rules Based on Real-Time Data." American Economic Review, September 2001, 91(4), pp. 964-85.

- "Monetary-Policy Rules and the Great Inflation." American Economic Review, May 2002a, 92(2), pp. 115-20. 


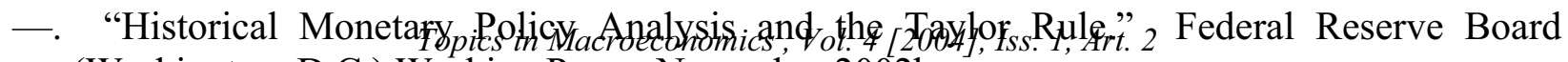
(Washington, D.C.) Working Paper, November 2002b.

-. "Monetary Policy Rules, Macroeconomic Stability and Inflation: A View from the Trenches." Journal of Money, Credit and Banking, forthcoming 2003.

- and John C. Williams. "Robust Monetary Policy Rules with Unknown Natural Rates." Brookings Papers on Economic Activity, 2002(2), pp. 63-118.

Perez, Stephen J. "Looking Back at Forward-Looking Monetary Policy." Journal of Economics and Business, 53, 2001, pp. 509-521.

Rotemberg, Julio J. and Woodford, Michael. "Interest Rate Rules in an Estimated Sticky Price Model," in Taylor (1999a), pp. 57-119.

Rudebusch, Glenn D. "Term Structure Evidence on Interest Rate Smoothing and Monetary Policy Inertia." Journal of Monetary Economics, September 2002, 49, pp. 1161-87.

Runkle, David E. "Revisionist History: How Data Revisions Distort Economic Policy Research.” Federal Reserve Bank of Minneapolis Quarterly Review, Fall 1998, 22(4), pp. 312.

Sack, Brian and Volker Wieland. "Interest Rate Smoothing and Optimal Monetary Policy: A Review of Recent Empirical Evidence." Journal of Economics and Business, 52, 2000, pp. $205-28$.

Taylor, John B. "Discretion versus Policy Rules in Practice." Carnegie-Rochester Conference Series on Public Policy, 39, December 1993, pp. 195-214.

—, ed. Monetary Policy Rules, Chicago: University of Chicago Press, 1999a.

—. “A Historical Analysis of Monetary Policy Rules," in Taylor (1999a), 1999b, pp. 319-41.

Woodford, Michael. "The Taylor Rule and Optimal Monetary Policy." American Economic Review, 91(2), May 2001, pp. 232-7. 